\title{
Neural Mechanisms of Placebo Anxiolysis
}

\author{
Benjamin Meyer, ${ }^{1,3}$ Kenneth S.L. Yuen, ${ }^{1,3}$ Matthias Ertl, ${ }^{2,4}$ Nenad Polomac, ${ }^{2}$ Christoph Mulert, ${ }^{2}$ Christian Büchel, ${ }^{1}$ \\ and Raffael Kalisch ${ }^{1,3}$ \\ ${ }^{1}$ Institute for Systems Neuroscience, and ${ }^{2}$ Department of Psychiatry and Psychotherapy, Psychiatry Neuroimaging Branch, University Medical Center \\ Hamburg-Eppendorf, 20246 Hamburg, Germany, ${ }^{3}$ Neuroimaging Center Mainz, Focus Program Translational Neuroscience, Johannes Gutenberg \\ University Medical Center, 55131 Mainz, Germany, and ${ }^{4}$ Department of Neurology and Graduate School for Systemic Neuroscience, University of Munich, \\ 81377 Munich, Germany
}

The beneficial effects of placebo treatments on fear and anxiety (placebo anxiolysis) are well known from clinical practice, and there is strong evidence indicating a contribution of treatment expectations to the efficacy of anxiolytic drugs. Although clinically highly relevant, the neural mechanisms underlying placebo anxiolysis are poorly understood. In two studies in humans, we tested whether the administration of an inactive treatment along with verbal suggestions of anxiolysis can attenuate experimentally induced states of phasic fear and/or sustained anxiety. Phasic fear is the response to a well defined threat and includes attentional focusing on the source of threat and concomitant phasic increases of autonomic arousal, whereas in sustained states of anxiety potential and unclear danger requires vigilant scanning of the environment and elevated tonic arousal levels. Our placebo manipulation consistently reduced vigilance measured in terms of undifferentiated reactivity to salient cues (indexed by subjective ratings, skin conductance responses and EEG event-related potentials) and tonic arousal [indexed by cue-unrelated skin conductance levels and enhanced EEG alpha $(8-12 \mathrm{~Hz})$ activity], indicating a downregulation of sustained anxiety rather than phasic fear. We also observed a placebo-dependent sustained increase of frontal midline EEG theta $(4-7 \mathrm{~Hz})$ power and frontoposterior theta coupling, suggesting the recruitment of frontally based cognitive control functions. Our results thus support the crucial role of treatment expectations in placebo anxiolysis and provide insight into the underlying neural mechanisms.

Key words: anxiety; EEG; event-related potentials; frontal midline theta; placebo effect

\section{Introduction}

A placebo effect is a psychobiological phenomenon occurring after the administration of an inactive treatment (e.g., inert substance, sham surgery) along with verbal suggestions of clinical benefit (Price et al., 2008). Over the last decades, there has been significant progress in our understanding of the neurobiological mechanisms underlying placebo effects (Benedetti et al., 2011), in particular in the treatment of pain (Büchel et al., 2014), but also of conditions such as Parkinson's disease (Benedetti et al., 2004; Schmidt et al., 2014) or depression (Leuchter et al., 2002). However, little is known about the neural bases of placebo effects in the treatment of fear and anxiety. This is remarkable, because in clinical everyday life placebos are frequently used with the intention to calm anxious patients (Nitzan and Lichtenberg, 2004; Sherman and Hickner, 2008) and placebo effects have been

\footnotetext{
Received Nov. 24, 2014; revised Feb. 20, 2015; accepted March 29, 2015.

Author contributions: B.M., K.Y., C.B., and R.K. designed research; B.M. and K.Y. performed research; C.M. contributed unpublished reagents/analytic tools; B.M., M.E., and N.P. analyzed data; B.M., M.E., N.P., C.M., C.B., and R.K. wrote the paper.

This work was supported by the Deutsche Forschungsgemeinschaft (DFG Grants KA 1623/3-1; FOR 1328, subproject 3; SFB TRR 58, subproject B03) and the European Research Council (Grant ERC-2010-AdG_20100407).

The authors declare no competing financial interests.

Correspondence should be addressed to Benjamin Meyer, Neuroimaging Center Mainz, Focus Program Translational Neuroscience, Johannes Gutenberg University Medical Center, Langenbeckstraße 1, Geb. 701, EG, Raum 0.035, 55131 Mainz, Germany. E-mail: benmeyer@uni-mainz.de.

DOI:10.1523/JNEUROSCI.4793-14.2015

Copyright $\odot 2015$ the authors $\quad 0270-6474 / 15 / 357365-09 \$ 15.00 / 0$
}

shown to contribute to the pharmacological treatment of anxiety disorders (Stein et al., 2006; Sugarman et al., 2014) and to the pharmacological reduction of postoperative anxiety (Benedetti et al., 2003; Colloca et al., 2004).

An early brain imaging study (Petrovic et al., 2005) could show that participants who believe to receive an anxiolytic and sedative drug react less aversively to unpleasant pictures and also have reduced picture-related neural activation. Together with a recent finding of placebo effects on picture-induced disgust and related neural responses (Schienle et al., 2014), this suggests that negative emotional states beyond pain, including their neural substrates, can be affected by placebo manipulations (Flaten et al., 2011).

Fear or anxiety are emotional reactions accompanying the anticipation of a harmful event (Grillon, 2008). In states of fear, attention, cognition, and response preparation are narrowed to a well defined threat that will occur with some predictability in a relatively circumscribed time window. Phasic fear states to discrete danger are to be distinguished from sustained states of anxiety where a potential and unclear threat requires vigilant scanning of the environment and risk assessment, supported by a more tonic state of arousal (Blanchard et al., 1993; Walker et al., 2003; Grillon, 2008).

We developed an experimental design (Fig. 1) that involves the anticipation over a period of $5 \mathrm{~s}$ of a previously experienced painful electrocutaneous stimulus signaled by a threat cue, to 
induce phasic fear. Several threat $(\mathrm{T})$ and no-threat (NT) trials (where no pain was to be expected) are presented in unpredictable order within experimental runs to create a threatening context that induces a sustained state of anxiety characterized by increased levels of arousal and vigilance. Participants apply a nasal spray at the beginning of each run, which is either labeled as containing a fast-acting anxiolytic (in placebo runs, $\mathrm{P}$ ) or saline (in no-placebo runs, NP; Fig. 1). In fact, both sprays only contain saline, and an anxiolytic is never applied.

In two studies, we found evidence for a placebo-related attenuated reactivity to salient cues (both T- and NT-cues) as indexed by subjective, autonomic, and electrophysiological measures (fear ratings, SCRs, EEG event-related potentials). Together with tonic increases of EEG-alpha power as an indicator of internalized attention (Klimesch et al., 2007) and reduced tonic skin conductance levels under placebo, this indicates a downregulation of symptoms typically associated with sustained anxiety rather than phasic fear. We further identified a neural signature classically associated with cognitive control (frontal midline theta power and frontoposterior theta coupling) that was elevated in P runs.

\section{Materials and Methods}

Participants. All participants were healthy, right-handed, and had no prior experience with psychopharmacological medications in a therapeutic context. In a first behavioral study (Study 1), 30 volunteers (mean age 25.7 years, age range $20-45$ years, 14 female) were enrolled. 29 further volunteers (mean age 26 years, age range 20-34 years, 14 female) participated in the following EEG study (Study 2). State and trait anxiety scores were assessed with the State-Trait Anxiety Inventory (Spielberger, 1985). Participants' trait anxiety scores ranged from 27 to 55 (mean \pm SD $38.1 \pm 6.1)$ in Study 1 and from 20 to $53(37.7 \pm 8.2)$ in Study 2. State anxiety before the experiment ranged from 23 to $51(33.6 \pm 6.4)$ in Study 1 and from 25 to $63(35.1 \pm 7.8)$ in Study 2. Before the experiment, participants rated the expected efficacy of the treatment. Participants who did not expect a beneficial effect were not further examined. This procedure reduced sample sizes to $N=28$ in Study 1 and $N=27$ in Study 2. Of these, $N=26$ and $N=23$, respectively, could be analyzed for effects on skin conductance and $N=24$ (Study 2) for effects on the EEG (see below). The Ethics Committee of the Medical Board in Hamburg, Germany, approved the study and all participants gave written informed consent. The consent form included information about the experimental procedures but did not include statements that participants would be deceived and that the purpose of the study was to investigate placebo anxiolysis. Participants were informed about these important aspects only during debriefing.

Procedure. The volunteers were informed that they would be participating in a clinical study examining the electrophysiological effects of lorazepam, a potent anxiolytic drug administered as a nasal spray. Lorazepam is in fact not available as nasal spray and was never administered in this experiment. To further induce positive treatment expectations, each participant received a fictive information brochure that informed about effects and potential side effects of lorazepam. Each participant received two differentially labeled nasal sprays that both contained normal saline. The placebo spray was labeled as a real drug and was marked with the uppercase letter "L," whereas a control spray was labeled as normal saline with the uppercase letter " $\mathrm{N}$ " $(\mathrm{NaCl})$. We told participants that perceived effects of the lorazepam spray appear after $\sim 30 \mathrm{~s}$ and last for 2-3 min. Participants then rated their treatment expectations on a visual analog scale (VAS) ranging from 0 (no expectation) to 100 (very high expectation). The experiment itself consisted of six runs under placebo (P runs) and 6 control runs (NP runs) in pseudo-randomized order (Fig. 1). Each run began with the instruction to apply the corresponding spray once into the indicated nostril. Instructions were presented for $45 \mathrm{~s}$ and followed by six to seven $\mathrm{T}$ and five NT trials. In T trials, participants knew they might receive a painful electric stimulus with a probability of $25 \%$ at any time during the $5 \mathrm{~s}$ that a red square was presented on the screen. One to two of the T trials per run were paired with a painful stimulus and later excluded from the analysis. In NT trials, a green square was presented for $5 \mathrm{~s}$ and participants knew they would not be stimulated. Trials were separated by a 5-8 s presentation of a fixation cross. A treatmentinduced reduction in fear of the painful electrocutaneous stimuli was explicitly suggested by the experimenter. Throughout $\mathrm{P}$ runs, an $\mathrm{L}$ was additionally presented on the screen to remind participants of the applied treatment, whereas in NP runs an $\mathrm{N}$ was presented. At the end of each run, participants rated their average level of fear for both $\mathrm{T}$ and NT trials on a VAS ranging from 0 (no fear/tension) to 100 (high fear/tension). The average duration of a single run was $2.3 \mathrm{~min}$. After six runs, participants paused for $3 \mathrm{~min}$.

Electrical stimulation. Painful electrical stimuli consisted of trains of three square wave pulses of $2 \mathrm{~ms}$ each, separated by $50 \mathrm{~ms}$ intervals. Pain stimuli were generated by a DS7A electrical stimulator (Digitimer) and delivered on the right dorsal hand through a surface electrode. In a prior calibration procedure, participants were asked to rate increasing stimulus intensities on a scale from 0 (no pain) to 10 (strong pain). An intensity corresponding to a pain level of 7 was used in the experiment.

Skin conductance recordings. Skin conductance (SC) time courses were recorded with a CED2502-SA SC unit (Cambridge Electronic Design; CED) and recorded with Spike 2 software (CED). Data were downsampled to 100 samples per second (sps) and denoised by applying a Butterworth low-pass filter with cutoff frequency of $20 \mathrm{~Hz}$ and additional Gaussian smoothing $(\sigma=40 \mathrm{~ms})$.

Skin conductance level and response analysis. SC signals can generally be described as consisting of two separable components, a slowly varying component (the SC level, SCL) and a rapidly varying component (the phasic SC responses, SCRs). The SCL reflects a tonic or background state of sympathetic arousal (Zahn et al., 1981; Boucsein et al., 2012), whereas SCRs are immediate sympathetic responses to discrete stimuli, such as threat cues (Büchel et al., 1998; Benedek and Kaernbach, 2010; Boucsein et al., 2012). To distinguish phasic fear-related responses induced by cue onset from sustained anxiety-related tonic arousal levels within a run, we decomposed SC time courses into a slowly varying tonic component $\mathrm{SC}_{\text {tonic }}$ and a rapidly changing phasic component $\mathrm{SC}_{\text {phasic }}$ using a deconvolution method implemented in the MATLAB toolbox Ledalab V344 (Benedek and Kaernbach, 2010). The applied method first deconvolves 


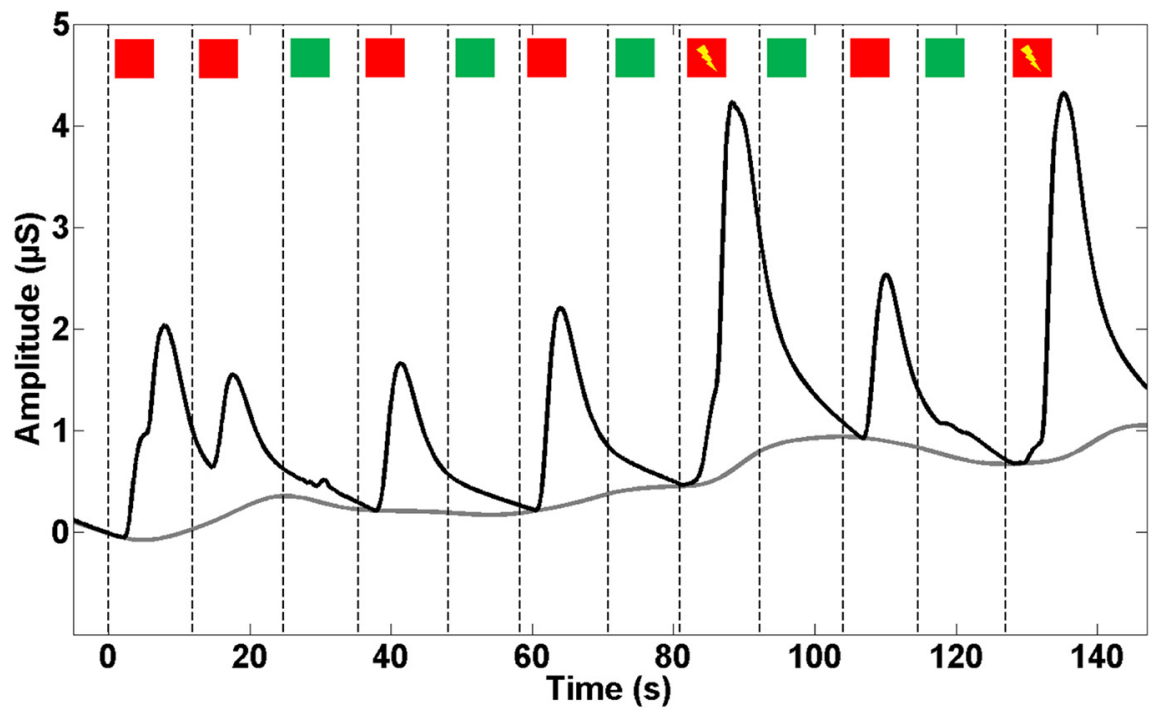

Figure 2. Example of a decomposed skin conductance time course. $\mathrm{SC}$ time course and underlying tonic component $\left(\mathrm{SC}_{\text {tonic }}\right)$ are represented by black and gray lines, respectively. The phasic component $\left(\mathrm{SC}_{\text {phasic }}\right)$ can be obtained by subtracting $\mathrm{SC}_{\text {tonic }}$ (gray line) from SC (black line). Dashed lines indicate trial onsets of T (red squares) and NT trials (green squares). Painful electric stimuli were applied in Trials 8 and 12.

the SC time course with an appropriate impulse response function (IRF) representing the standard SCR shape. This yields an estimate of the underlying function triggering phasic SCRs ( Driver $_{\mathrm{SC}}$ ). Interimpulse sections in Driver ${ }_{\mathrm{SC}}$, where no SCRs are generated, are then used to estimate a tonic driver function ( Driver $_{\text {tonic }}$ ) by an interpolation proce-

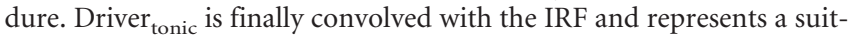
able measure of the underlying SCL $\left(\mathrm{SC}_{\text {tonic }}\right)$ exempt from rapidly changing SCRs. Subtracting $\mathrm{SC}_{\text {tonic }}$ from SC leads to an estimate of the phasic activity $\left(\mathrm{SC}_{\text {phasic }}\right)$, which in turn does not contain any slow $\mathrm{SC}$ variations. An example for a decomposed time course is shown in Figure 2. SCL was defined as the average $\mathrm{SC}_{\text {tonic }}$ ranging from the onset of the first cue in a run to the onset of the rating phase minus the average $\mathrm{SC}_{\text {tonic }}$ in a $1 \mathrm{~s}$ time window before the first cue. Values were $z$-transformed and averaged for each participant. SCRs were manually scored from $\mathrm{SC}_{\text {phasic }}$ by using a custom-made computer program. SCR amplitudes in microsiemens $(\mu \mathrm{S})$ were scored as the first response occurring from 0.9 to $4 \mathrm{~s}$ after cue onset with minimal response amplitude of $0.02 \mu \mathrm{S}$. Values were logarithmically transformed and log values were range corrected $(\log (1$ $+\mathrm{SCR} / \mathrm{max}$ ) to account for intra- and interindividual variability (Lykken and Venables, 1971). A complete lack of any threat-induced SCRs, excessive baseline activity and a technical problem in one participant led to the exclusion of two participants in Study 1 and four participants in Study 2. Finally, SC data from 26 participants in Study 1 and 23 participants in Study 2 were analyzed.

Statistical analyses of behavioral data. Statistical analyses of behavioral data were performed by repeated-measures ANOVA using the free software environment R (v3.0.0). Main and interaction effects were defined by the following contrasts:

Main effect of threat: $[\mathrm{T} / \mathrm{P}+\mathrm{T} / \mathrm{NP}]-[\mathrm{NT} / \mathrm{P}+\mathrm{NT} / \mathrm{NP}]=\mathrm{T}-\mathrm{NT}$

Main effect of placebo: $[\mathrm{T} / \mathrm{P}+\mathrm{NT} / \mathrm{P}]-[\mathrm{T} / \mathrm{NP}+\mathrm{NT} / \mathrm{NP}]=\mathrm{P}-\mathrm{NP}$

Threat by placebo interaction: $[\mathrm{T} / \mathrm{P}-\mathrm{NT} / \mathrm{P}]-[\mathrm{T} / \mathrm{NP}-\mathrm{NT} / \mathrm{NP}]=$ $\Delta \mathrm{T}_{\mathrm{P}}-\Delta \mathrm{T}_{\mathrm{NP}}$

Significant effects ( $\alpha$-threshold $=0.05$ ) were further characterized by one-tailed Student's $t$ tests. Subdivision into high (HR) and low (LR) placebo responders was done by median split on the main effect of placebo contrast in fear ratings.

EEG recordings and preprocessing (Study 2 only). Recordings took place in a sound-attenuated and electrically shielded room. Participants were seated in a slightly reclined chair in front of a 19 inch computer monitor and asked to keep their eyes open. The distance between the participant's eyes and the monitor was $\sim 1 \mathrm{~m}$. Data were collected at a rate of $1000 \mathrm{sps}$ with 66 active electrodes mounted on an elastic cap (ActiCaps, Brain
Products) using the Brain Vision Recorder software v1.10 (Brain Products). Electrodes were arranged according to a modified 10/10 system without electrodes at the positions $\mathrm{FPz}$, F9, F10, T9, T10, CP3, CP4, P9, P10, PO7, PO8, and with additional electrodes at positions PO9 and PO10. Eye movements were recorded through four EOG channels (positioned at the outer canthi bilaterally and infra- and supraorbitally on the right). An electrode at the $\mathrm{FCz}$ position was used as the reference, the electrode at position AFz served as ground. Impedances were always kept $<5 \mathrm{k} \Omega$. Data were preprocessed by using the MATLAB toolbox fieldtrip (v20131120; Oostenveld et al., 2011). Every trial was subdivided into precue and postcue epochs ranging from 3500 to $0 \mathrm{~ms}$ before trial onset (used as the intertrial interval, ITI) and from $500 \mathrm{~ms}$ before trial onset to 1500 ms after trial onset, respectively. Before epoching continuous datasets were bandpass filtered with cutoff frequencies of 0.1 and $40 \mathrm{~Hz}$ for frequency analyses on precue data and lowpass filtered with a cutoff frequency of $40 \mathrm{~Hz}$ for ERP-analyses on postcue data. Data were down-sampled to 250 sps, re-referenced to the common average, and an independent component analysis was applied to remove eye-blinks, as well as horizontal eye-movements from epochs. Data were finally baseline-corrected to the average of 3500-3000 ms before trial onset for precue epochs (ITIs) and to the average of $500-0 \mathrm{~ms}$ before trial onset for postcue epochs. Trials that continued to contain residual artifacts were removed from further analyses. ERP analyses were performed on postcue epochs and frequency power analyses were performed on precue epochs. Three participants were excluded from further EEG analyses due to excessive artifacts. EEG data from 24 participants were finally analyzed.

ERP analysis. Event-related potentials (ERPs) of interest were predefined based on a pilot study $(N=20)$, where $60 \mathrm{~T}$ and $60 \mathrm{NT}$ trials were presented without any placebo manipulation. We visually selected three time windows and corresponding electrode sets showing pronounced positive deflections under threat (T-NT): P100 (electrodes: POz, PO3-4, PO9-10, Oz, O1-2; time window: 100-140 ms), P300, and LPP (electrodes: CPz, CP1-2, CP5-6, TP7-10, Pz, P1-8, POz, PO3-4, PO9-10, Oz, O1-2; time windows: $280-400$ and $400-700 \mathrm{~ms}$, respectively). Each averaged selection revealed a strong main effect of threat in the pilot study $\left(\mathrm{P} 100: t_{(19)}=4.544, p<0.001 ; \mathrm{P} 300: t_{(19)}=5.278, p<0.001\right.$; LPP: $\left.t_{(19)}=8.495, p<0.001\right)$. Our ERP definitions are comparable with other studies on P100 (Di Russo et al., 2002), P300, and LPP (Hajcak et al., 2010; Scharmüller et al., 2012) components, though, depending on the exact type of cue, time windows might slightly differ. To account for the multiple-comparison problem, we used nonparametric cluster-based permutation tests (Maris and Oostenveld, 2007) on corresponding $t$ statistics for either the whole sample (one-sample $t$ tests) or for the comparison of HRs and LRs (two-sample $t$ tests). Electrodes with $p$ values $<0.05$ were considered as candidate members of a cluster. Cluster-level statistics were calculated by taking the sum of the $t$ values within every cluster. The number of randomizations was set to 5000 and cluster $p$ values smaller than a critical alpha-level $\alpha=0.05$ indicated significant effects.

Frequency power and coupling analysis. We analyzed EEG alpha power $(8-12 \mathrm{~Hz})$ in the ITIs to ask whether alpha oscillations as an indicator of internal as opposed to external attention (Cooper et al., 2003; Klimesch et al., 2007) were enhanced in $\mathrm{P}$ runs in a temporally sustained fashion. Baseline-corrected segments of 3000-0 ms before trial onset were extracted from precue epochs (see EEG recordings and preprocessing), Hanning-windowed and fast Fourier transformed (FFT; $1 \mathrm{~Hz}$ resolution). Differences between alpha power in $\mathrm{P}$ and NP runs were assessed by two-tailed Student's $t$ tests, and cluster-based analyses on all electrodes were used to correct for multiple comparisons as described in ERP analysis. 
To evaluate the hypothesis that frontal cognitive control mechanisms contribute to placebo anxiolysis, we asked whether ITI frontal midline theta (FMT; $4-7 \mathrm{~Hz}$ ) oscillations as a well described measure of internally directed cognitive control (Hsieh and Ranganath, 2014) were enhanced in P runs. We additionally analyzed frontoposterior theta coupling (FPTC; $4-7 \mathrm{~Hz}$ ) assessed with the phase locking value (PLV) during ITIs, which has been introduced as representing corticocortical information flow organized under executive prefrontal control (Sauseng et al., 2007; Anguera et al., 2013). We focused our analysis on electrode Fz, which typically shows maximal activity under sustained internally directed cognitive control (Hsieh and Ranganath, 2014). FMT power was calculated as mean theta power $(4-7 \mathrm{~Hz})$ of electrode Fz. Complex FFT coefficients were further used to calculate PLVs between electrode $\mathrm{Fz}$ and all posterior electrodes $(\mathrm{CPz}$, CP1-2, CP5-6, TP7-10, Pz, P1-8, POz, PO3-4, PO9-10, Oz, O1-2) as described by Lachaux et al. (1999). The PLV ranges between 0 and 1 , with 0 meaning no phase coupling and 1 meaning absolute phase coupling between two electrodes. PLVs corresponding to $4-7 \mathrm{~Hz}$ were averaged. Differences between PLVs of P and NP runs were assessed by two-tailed Student's $t$ tests for each combination of electrode $\mathrm{Fz}$ and all posterior electrodes. To correct for multiple comparisons, again cluster-based analyses as described above were applied to identify clusters exhibiting increased coupling with electrode Fz.

\section{Results}

Behavioral results

Study 1 (behavioral study)

Fear ratings (Fig. $3 A$ ) revealed a successful induction of phasic fear by the threatpredicting cues (Fig. 1, red squares; main effect of threat, T-NT: $F_{(1,27)}=355.2, p<$ $0.001)$. The expectation of anxiolysis by the nasal spray produced both a main effect of placebo (P-NP: $F_{(1,27)}=15.9, p<$ $0.001)$, and a threat by placebo interaction $\left(F_{(1,27)}=15.36, p<0.001\right)$. This pattern was qualified by a pronounced placeboinduced decrease of felt fear in threat trials $\left(\mathrm{T} / \mathrm{P}-\mathrm{T} / \mathrm{NP}: t_{(27)}=-4.044, p<0.001\right.$, one-tailed post hoc $t$ test), which was, how-

ever, accompanied by a significant (albeit less pronounced) decrease also in no-threat trials (NT/P-NT/NP: $t_{(27)}=-2.7, p=$ 0.006 ). Fear ratings were generally low in NT trials (Fig. $3 A$ ), leaving the possibility of a floor effect that might have masked placebo-related reductions in those trials, thus producing an artificial interaction. It thus remained unclear whether the anxiolytic placebo acted mainly by attenuating a cue-unspecific state of aversion or arousal (in both T and NT trials) or also genuinely affected threat cue-specific phasic fear (in T trials only). In-line with fear ratings, phasic SCRs (Fig. $3 B$ ) to the threat and nothreat cues showed again main effects of threat $\left(\mathrm{T}-\mathrm{NT}: F_{(1,25)}=\right.$ $163.8, p<0.001)$ and placebo (P-NP: $\left.F_{(1,25)}=5.337, p=0.0294\right)$ but only a nonsignificant, though trend-like interaction $\left(F_{(1,25)}=\right.$ 3.963, $p=0.058)$, again leaving open the question of a genuine
Study 1
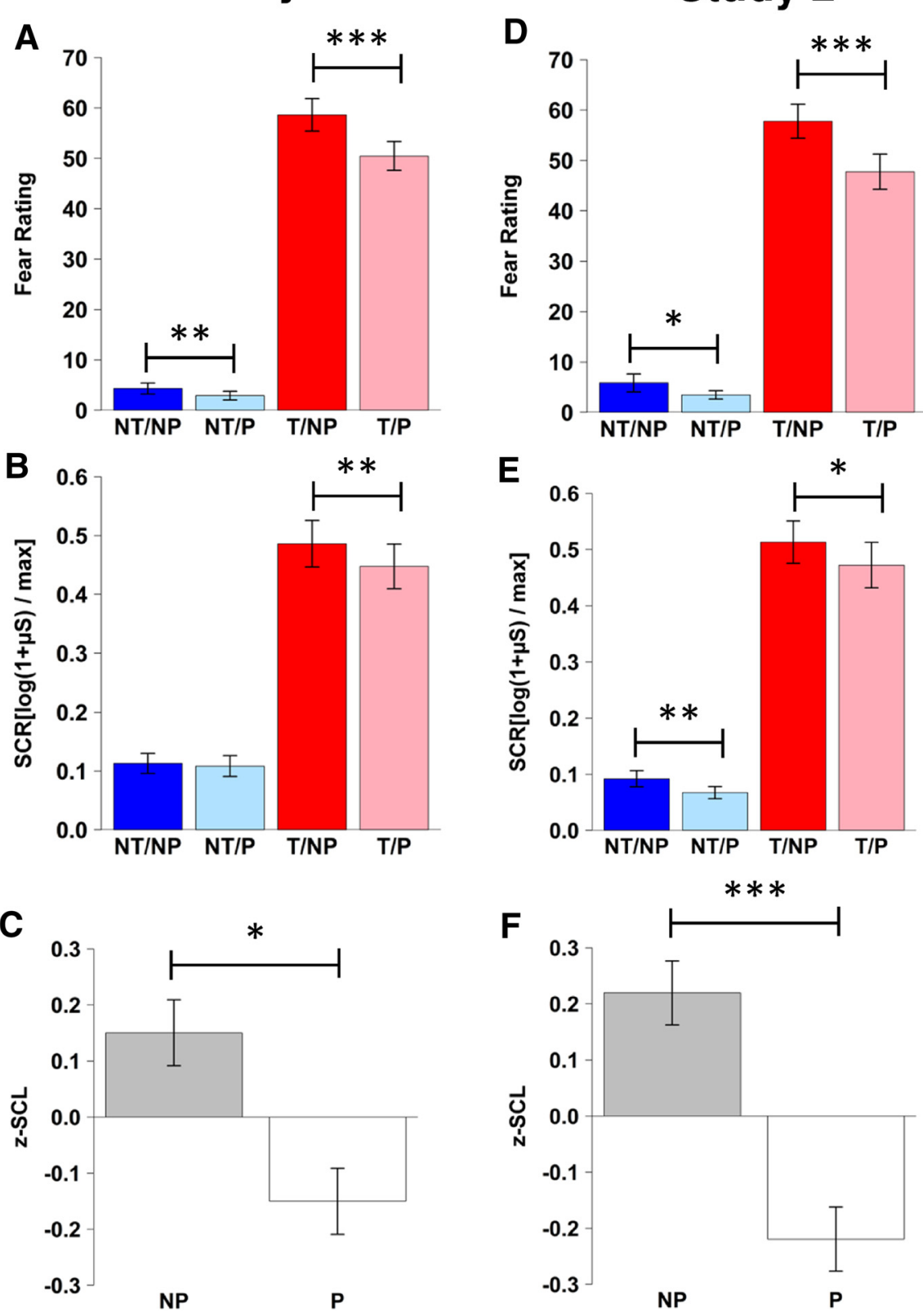

Figure 3. Behavioral results (Studies 1 and 2). In both studies, fear ratings $(\boldsymbol{A}, \boldsymbol{D})$ and $\operatorname{SCRs}(\boldsymbol{B}, \boldsymbol{E})$ to the cues revealed main effects of placebo (P-NP), indicating a cue-unspecific placebo effect. Tonic SCLs measured throughout experimental runs $(\boldsymbol{C}, \boldsymbol{F})$ showed reduced arousal under placebo (P-NP); ${ }^{*} p<0.05 ;{ }^{* *} p<0.01 ;{ }^{* * *} p<0.001$. Error bars indicate SEM.

effect on threat cue-specific responses. Clearly supporting a cueunspecific placebo action, tonic SCLs (Fig. 3C; see Materials and Methods for details) throughout each of the 12 experimental runs were also reduced after application of the placebo spray (P runs) relative to the control spray (NP runs; $t_{(1,25)}=-2.553, p=0.017$, two-tailed $t$ test). Hence, participants appeared to be tonically less aroused and reactive to any salient event in the experiment (i.e., less vigilant) when under the illusion of an active anxiolytic treatment.

\section{Study 2 (EEG study)}

Cue-unspecific placebo effects presumably indicating reduced vigilance were also evident in the EEG study, whereas there was again only limited support for genuine actions on threat cuespecific responses. As in Study 1, both fear ratings (Fig. 3D) and 


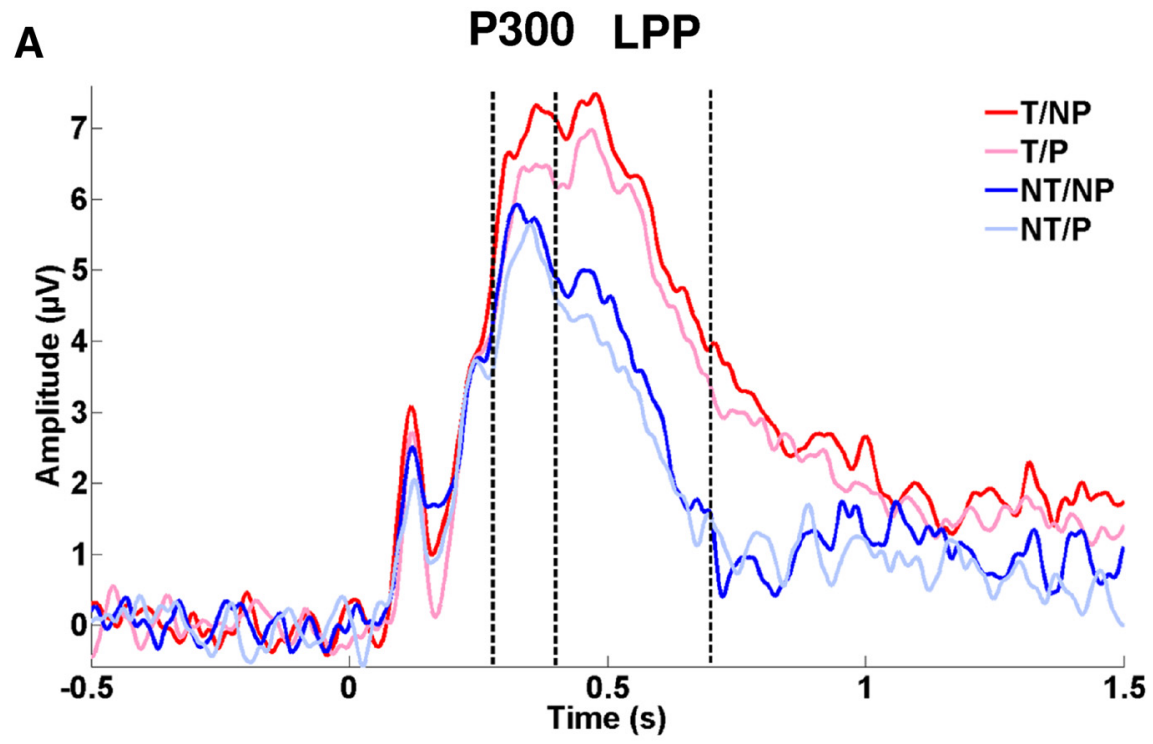

B

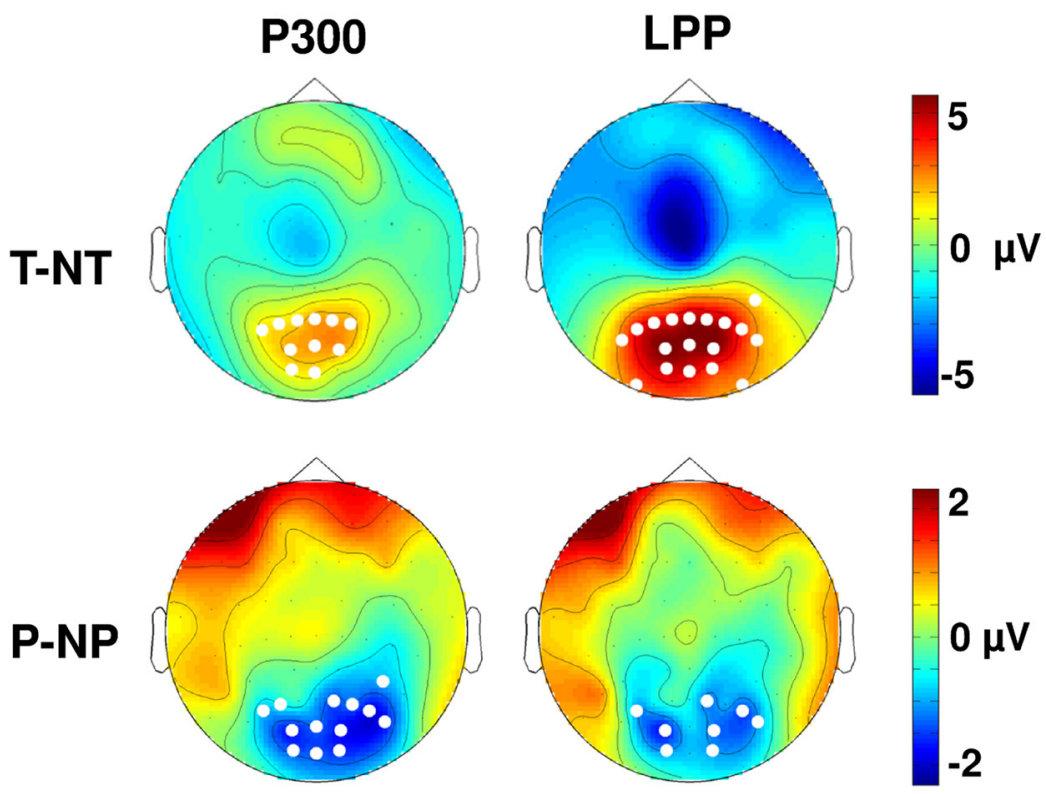

Figure 4. $\quad \operatorname{ERPS}($ Study 2). Average activation time courses of electrode P4 time-locked to cue onset (0s). Significant main effects of threat (T-NT, red-blue curves) and placebo (P-NP, light-dark curves) were found for the P300 and for the LPP components ( $\boldsymbol{A}$ ). Topographic voltage difference maps for the threat and placebo main effects (T-NT: voltage increases, red; P-NP: voltage reductions, blue) in P300 and LPP (B). White dots indicate electrodes of significant clusters $(p<0.05)$.

SCRs (Fig. 3E) showed main effects of threat (T-NT; ratings: $F_{(1,26)}=259.1, p<0.001$; SCRs: $\left.F_{(1,22)}=153.9, p<0.001\right)$ and placebo (P-NP; ratings: $F_{(1,26)}=18.98, p<0.001$; SCRs: $F_{(1,22)}=$ $8.208, p=0.009)$, with an interaction appearing only in fear ratings $\left(F_{(1,26)}=19.4, p<0.001\right)$ but not in SCRs $\left(F_{(1,22)}=0.867\right.$, $p=0.362$ ). Also, tonic SCLs (Fig. $3 F$ ) were again globally reduced by the placebo (P-NP: $t_{(22)}=-3.847, p<0.001$, two-tailed).

\section{EEG results (Study 2)}

Threat cue-specific versus cue-unspecific responses

To search for potential genuine placebo actions on responses specifically to the threat-predicting cues, we examined predefined threat-responsive ERPs; see Materials and Methods). Cluster-based permutation tests revealed significant main effects of threat (T-NT) for all predefined ERPs: P100 ( $p=0.004)$, P300 $(p=0.004$; Fig. $4 B)$, and LPP $(p<0.001 ;$ Fig. $4 B)$. There was no modulation of the P100 component by the placebo, suggesting our placebo manipulation did not affect basal sensory processes. The P300 component showed main effects of placebo (P-NP) both when analyzing the electrode exhibiting the strongest threat main effect (electrode P4: $F_{(1,23)}=7.039, p=0.0139$; Fig. $4 A$ ) but also when performing a cluster-based permutation test (see Materials and Methods) within the prespecified electrode set $(p=0.002$; Fig. $4 B)$. However, no threat by placebo interactions could be identified with either approach. Like the P300 component, the LPP component also showed a placebo main effect in the cluster-based analysis $(p=0.012$; Fig. $4 B)$, and like all other components, no interaction. The absence of detectable threat cue-specific placebo effects in ERPs mirrors the behavioral results, whereas the observation of placebo main effects again indicates that our placebo manipulation acted globally on cue reactivity.

Further highlighting a consistent effect on unspecific cue reactivity across both behavioral and neural measures, the P300 placebo main effect in the most threatresponsive electrode (P4) was predicted by participants' pre-experimental treatment expectation ratings $\left(r=-0.56, p_{\text {Pear }}\right.$ $=0.005$; Fig. $5 A$ ); i.e., there was an inverse relationship between the expected treatment efficacy and the reactivity to salient cues (vigilance). The P300 effect also correlated significantly with the main effect of placebo in fear ratings $\left(r=0.445, p_{\text {Pear }}\right.$ $=0.029$; Fig. $5 B$ ). This result remained valid when reducing the effect of strong fear rating outliers by robust regression (Huber, 1981; $p_{\text {rob }}=0.037$ ).

\section{Cue-unrelated activity}

The observation of tonically reduced arousal (as evidenced by lower SCLs in placebo runs, see above) in combination with reduced unspecific cue reactivity suggests attenuation of a sustained state of vigilance or undirected anxiety as the primary effect of our placebo treatment. We therefore analyzed EEG alpha power $(8-12$ $\mathrm{Hz}$ ) in the ITIs (see Materials and Methods) to ask whether alpha oscillations, an indicator of internally as opposed to externally directed attention (Cooper et al., 2003; Klimesch et al., 2007), were enhanced in $\mathrm{P}$ runs in a temporally sustained fashion. Cluster-based analyses revealed an increase in alpha power under placebo $(p=0.041)$ that was only driven by placebo HRs (see Materials and Methods; $p=0.011$ ), leading to a significant difference between HRs and LRs ( $p=0.014$; Fig. 6).

\section{Frontal theta power}

A possible cognitive working mechanism, not necessarily incompatible with internal attentional focusing, is that participants exploited the suggested expectations of anxiolysis to exert cognitive control over their anxiety. To test this hypothesis, we analyzed 
$\mathrm{A}_{4}$
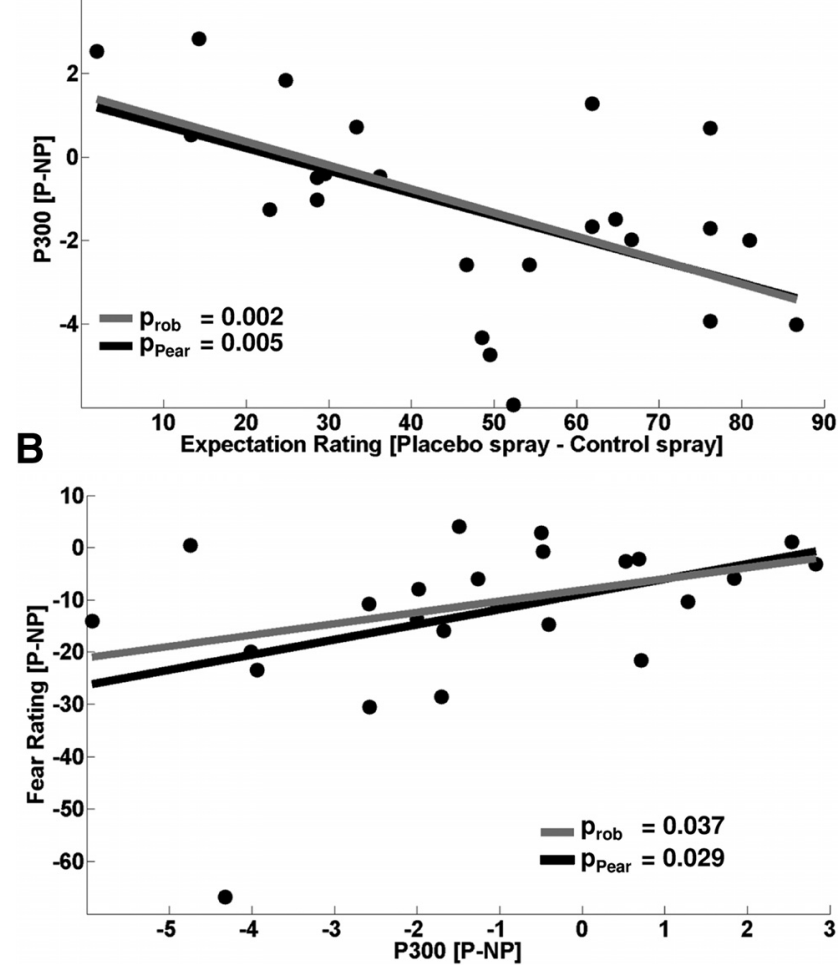

Figure 5. Brain-behavior correlations (Study 2). The reduction of P300 amplitudes under placebo in electrode $\mathrm{P} 4$ was predicted by pre-experimental treatment expectations $(\boldsymbol{A})$ and also correlated with the placebo main effects in fear ratings across participants $(\boldsymbol{B}) . p_{\text {Pear }}, p$ Value of Pearson's correlation; $p_{\text {rob }}, p$ value of robust correlation.

theta power in electrode $\mathrm{Fz}$ (FMT power) and FPTC in the ITIs (see Materials and Methods). FMT power was represented by a distinct peak in the spectrum of electrode Fz between 4 and 7 $\mathrm{Hz}$ when averaging over both $\mathrm{P}$ and NP runs (Fig. $7 A$ ). We tested multiple classical frequency bands (delta $=1-3 \mathrm{~Hz}$, theta $=4-7 \mathrm{~Hz}$, alpha $=8-12 \mathrm{~Hz}$, beta $1=13-20 \mathrm{~Hz}$, beta $2=$ 21-30 Hz, gamma $=31-40 \mathrm{~Hz}$ ), but only theta power was enhanced in $\mathrm{P}$ runs relative to NP runs $\left(t_{(1,23)}=3.198, p=\right.$ 0.004 two-tailed, $\alpha_{\text {Bonferroni }}=0.008$; Fig. $\left.7 B\right)$. This effect differed significantly between HRs and LRs $\left(F_{(1,22)}=8.534, p=\right.$ 0.008 ; Fig. $7 B$ ). This was accompanied by enhanced FPTC between electrode $\mathrm{Fz}$ and a cluster of posterior electrodes $(p=$ $0.024)$. Increased FPTC was again only present in HRs ( $p=$ 0.027), but not in LRs (Fig. 7B).

\section{Discussion}

In this study, we successfully induced an anxiolytic placebo effect by coupling an inert medication with a verbally suggested expectation of anxiolysis. Our placebo manipulation solely relied on explicit verbal information, as opposed to manipulations that additionally involve a phase of conditioning before the test phase. In the latter class of studies, participants are initially made to experience symptom relief (such as a heat pain reduction) in the presence of the placebo but caused by some other manipulation (such as a surreptitious lowering of the applied temperature), which results in a (false) attribution of the relief experience to the placebo (Eippert et al., 2009). We chose a purely verbal manipulation to emulate a frequent clinical situation and to facilitate the interpretation of possible placebo effects as only reflecting an explicit treatment expectation. Using this manip-
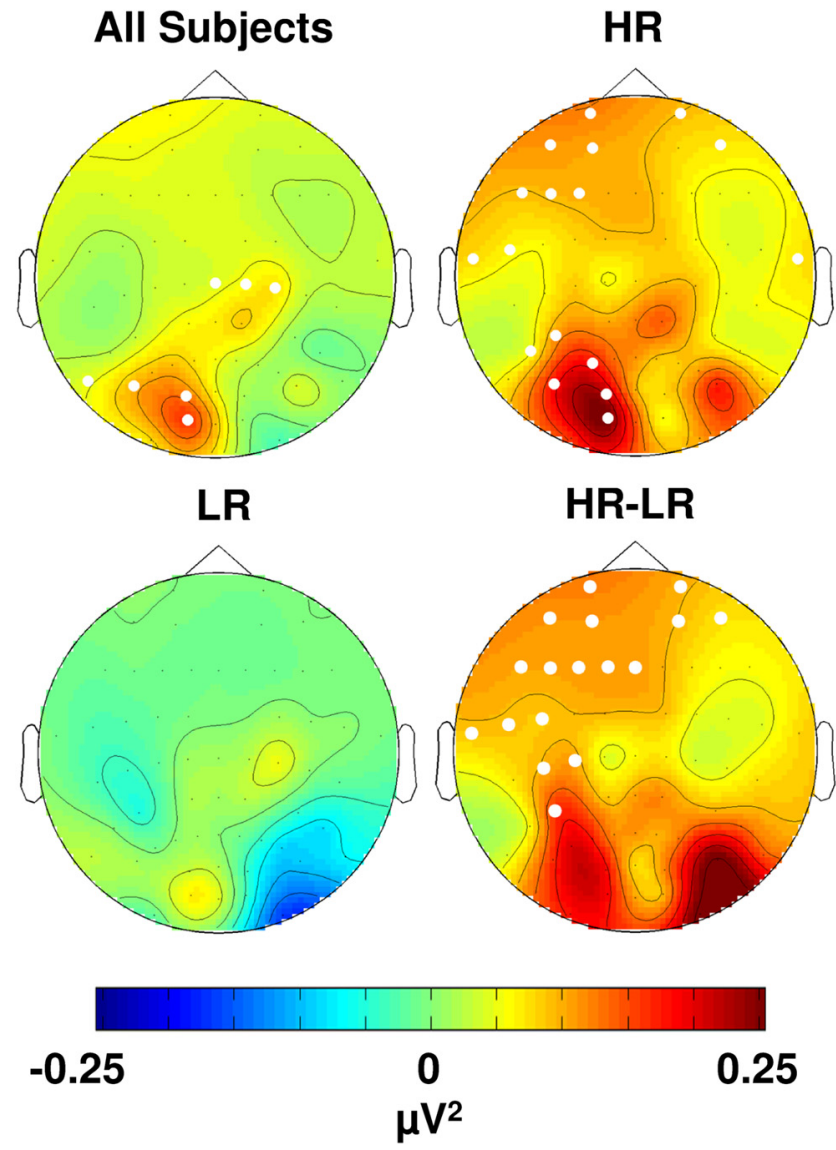

Figure 6. ITI alpha activity (Study 2). ITI alpha activity was increased in placebo relative to no placebo runs (P-NP) for the total sample. Only HRs but not LRs showed increased alpha activity in placebo runs. A widespread frontal cluster revealed significant differences between HRs and LRs (HR-LR). White dots indicate electrodes of significant clusters $(p<0.05)$.

ulation, we obtained consistent evidence for reduced levels of sustained arousal and vigilance as indicated by lowered tonic autonomic activity (SCLs) and heightened ITI alpha power and by attenuated subjective (fear ratings), peripheral (SCRs), and neural (P300, LPP) cue reactivity. The attenuation in cue reactivity was unspecific in that it was observed to both threat and no-threat cues. There was also a tonic enhancement of neural signatures typically representing frontal cognitive control (ITI, FMT, and FPTC) which might play a major role in placebo anxiolysis.

The seminal studies by Petrovic et al. (2005) and Schienle et al. (2014) have already provided evidence that placebo effects are not restricted to pain but can also be observed in other aversive states. More closely addressing the concept of fear/anxiety, Furmark et al. (2008) has shown reductions in amygdala reactivity to public speaking from before to after receiving chronic placebo treatment as part of a randomized clinical drug trial in social anxiety disorder patients. Amygdala reductions were dependent on serotonin-related gene variants. However, the study design did not permit to distinguish between actual placebo-related and mere time-related changes (e.g., habituation, extinction). The current study was therefore designed to examine the effects of a pure placebo manipulation specifically on threat responses (i.e., fear/anxiety) in healthy participants under well defined controlled laboratory conditions.

A first fundamental question that arises in the mechanistic study of placebo anxiolysis is whether placebo manipulations 


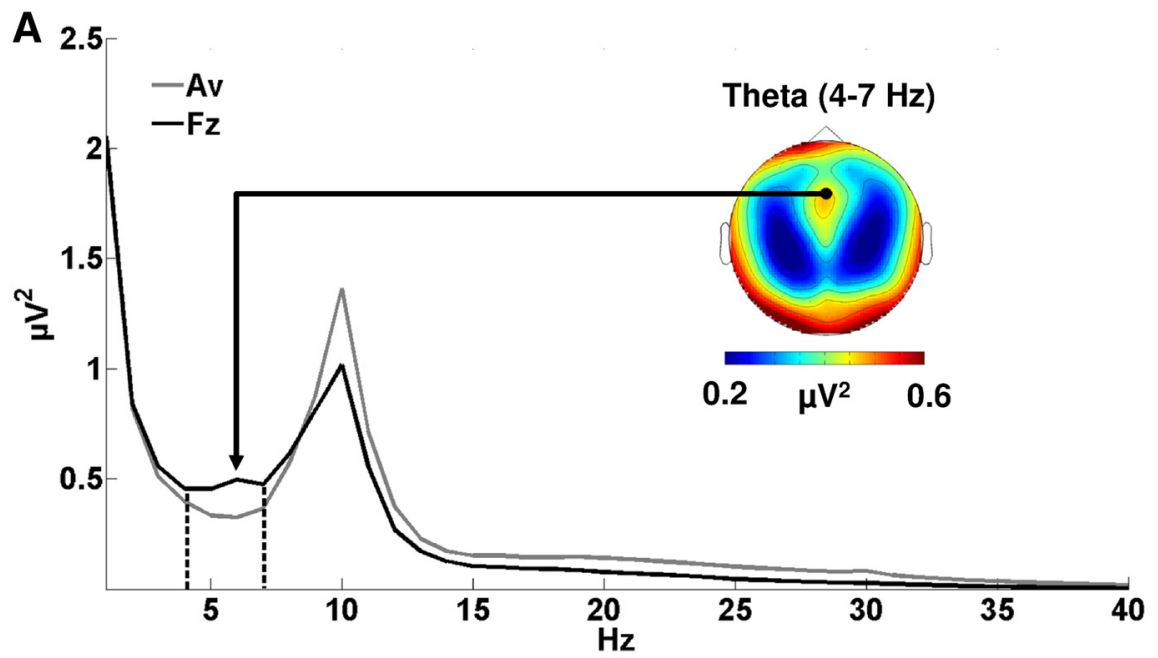

B

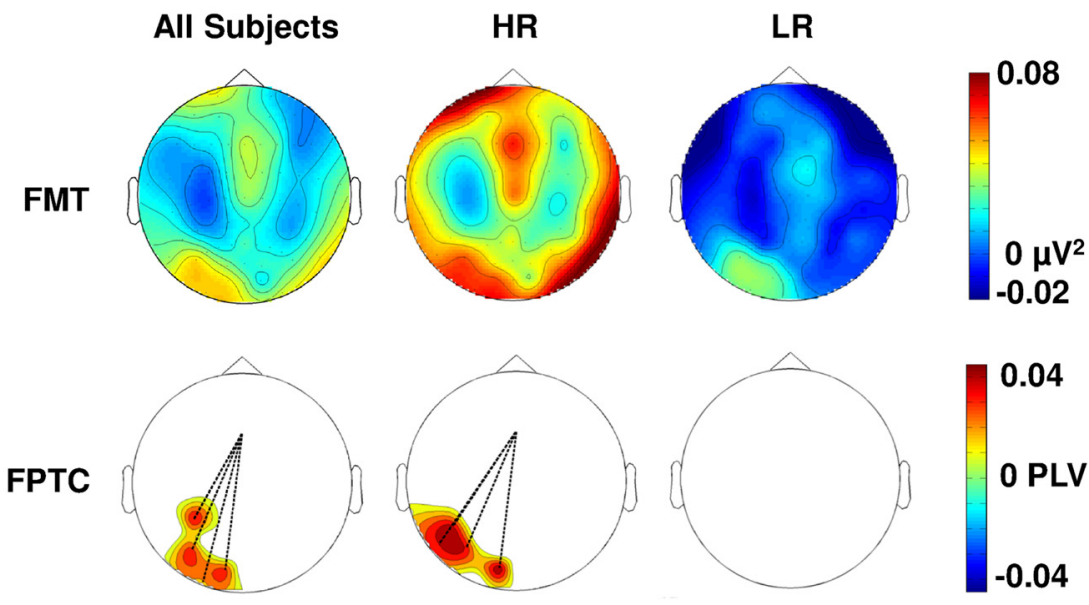

Figure 7. ITI theta activity (Study 2). Illustration of the ITI power spectrum collapsed across $\mathrm{P}$ and NP runs of electrode Fz and the average of all electrodes (Av). Overall power in the theta band was elevated in frontal midline channels including electrode Fz $(\boldsymbol{A})$. FMT power was increased during ITIs in placebo relative to no-placebo runs (P-NP) for the total sample (left column). FPTC was also enhanced in placebo runs. Middle and right columns: HR and LR placebo responders. Significant coupling between cluster electrodes and electrode Fz is indicated by dashed lines. Noncluster electrodes are masked in FPTC results $(\boldsymbol{B})$.

affect fear or anxiety or both. Ethologists have long made a distinction between fear responses to imminent threats (such as the presence of a predator), which often involve flight or fight, and more sustained anxiety responses to distal or potential threats (such as the odor of a predator), often involving vigilant scanning and risk assessment (Fanselow and Lester, 1988; Blanchard et al., 1993; Rodgers, 1997). Both types of behaviors are supported by partly separable neurochemical systems and neural circuits (Blanchard et al., 1993; Walker et al., 2003; Davis et al., 2010). A similar distinction in humans emphasizes the phasic recruitment of focused attention and cognition and the preparation of reflexlike defense responses, accompanied by a sudden surge in arousal, when a threat is near and identifiable (fear), and the heightening of overall sensory sensitivity and vigilance and the production of avoidance behaviors, accompanied by tonic arousal, when a threat is more unpredictable (anxiety; Mobbs et al., 2007; Grillon, 2008). Clinically, this may correspond to specific phobic responses versus generalized distress, anxiety, and worry, only the latter of which are sensitive to benzodiazepines (Grillon, 2008). Our data do not fully exclude attenuating effects of our verbal placebo manipulation on phasic fear responses, potentially evident from the threat by placebo interaction effects in subjective fear ratings, indicating a threat cue-specific placebo action. However, we obtained clear evidence for the downregulation of unspecific cue reactivity, or vigilance (in the placebo main effects in fear ratings, SCRs, P300, LPP), as well as of tonic arousal (in SCLs and ITI alpha power). These findings indicate a placebo action on sustained anxiety responses.

On the basis of a preferential placebo action on anxiety-related symptoms (at least in our paradigm), a second fundamental question is which neural substrates of anxiety responses are affected (downregulated) by placebo anxiolysis. We here observed a reduction specifically of later ERPs, in particular the P300 component, to both threat and no-threat cues. The P300 (280-400 ms), like the subsequent LPP (400-700 ms), is considered a measure of allocation of attention and working memory resources toward salient external stimuli, making it a suitable measure of individual vigilance levels (Polich, 2007; Hajcak et al., 2010). So, P300 potentials have been extensively studied in oddball paradigms (Johnson, 1984; Magliero et al., 1984; Mulert et al., 2004) but also during threat of shock (Baas et al., 2002; Weymar et al., 2013) or in symptom provocation in phobics (Kolassa et al., 2005; Scharmüller et al., 2011). The P300 amplitude can be modulated by the general arousal level (Polich and Kok, 1995) and concurrent cognitive demands (Isreal et al., 1980; Brookhuis et al., 1981; Kok, 2001); i.e., the P300 decreases when arousal is low and concurrent cognitive demands are high. In response to emotional stimuli the P300 is often followed by a sustained ongoing late positive potential (LPP) (Hajcak et al., 2010; Liu et al., 2012). Like the P300, the LPP did not show a threat cue-specific placebo modulation and was characterized by similar topographies. It might thus well be that both potentials can be ascribed to the same neural generators and should be considered a functional unit.

In-line with an interpretation of reduced anxiety-related vigilance and concomitant tonic arousal as neural effects of the placebo treatment, we also found widespread placebo-induced increases in precue (ITI) alpha activity, traditionally considered an "idling rhythm" that indicates reduced cortical activity (Pfurtscheller et al., 1996). Research over the last three decades has found evidence for an additional, more specific function of alpha oscillations (Cooper et al., 2003; Klimesch et al., 2007). Based on data mainly from working memory tasks, Klimesch et al. (2007) suggested that alpha activity can inhibit nontask relevant cortical areas, a process necessary for a wide range of demanding cognitive processes and supporting the internal focusing of attention. Rather than being a mere secondary consequence of the placebo treatment, sustained alpha increases might therefore also actively contribute to the placebo effect. 
This pertains to the third fundamental question in the study of placebo anxiolysis mechanisms, which is whether there may be active mechanisms at the neural level that mediate anxiolytic placebo instructions. The best candidate for such a neurocognitive working mechanism in our study was a sustained increase (seen during ITIs in placebo relative to no-placebo runs) in FMT and FPTC. Frontal theta oscillations are observed in tasks requiring internalized attention and cognitive control, for instance when participants are asked to retain items in working memory (Gevins et al., 1997; Hsieh et al., 2011) but also when regulating emotional states by reappraisal or meditation techniques (Aftanas and Golocheikine, 2001; Ertl et al., 2013). Theta phase coupling between frontal and posterior sites is generally considered an indicator of corticocortical information flow (Sauseng et al., 2007) and was also reported as a measure of cognitive control (Anguera et al., 2013). We therefore suggest that placebo anxiolysis is an active process requiring top-down cognitive control, supported mainly by frontal substrates. In-line with this hypothesis, functional magnetic resonance imaging (fMRI) studies of placeboinduced reductions in pain and other negative emotional states have consistently found placebo-induced activations in prefrontal and anterior cingulate sites, often correlated with the magnitude of the placebo effect (Wager et al., 2004; Petrovic et al., 2005; Bingel et al., 2006; Zhang et al., 2011; Amanzio et al., 2013) and disruption of prefrontal activity during placebo tasks has been shown to disrupt placebo effects (Benedetti, 2010; Krummenacher et al., 2010).

Some limitations of the study should be mentioned. Exact sources of placebo-related FMT power changes were not localized, and due to volume conduction and common reference effects FPTC results should be interpreted with caution (Nunez et al., 1997). We used FMT power and FPTC as biomarkers of cognitive control. Cognitive control is a broad and multifaceted construct, and aspects of cognitive control contribute to a wide range of behaviors, from simple working memory performance to complex skills, such as cognitive emotion regulation (Ochsner and Gross, 2005). Many of these behaviors are associated with enhanced frontal theta oscillations (Ertl et al., 2013; Hsieh and Ranganath, 2014), and we are unable here to distinguish between these possibilities. We can therefore only speculate that our neural indices of active cognitive control might correspond to states of attentional distraction from the anxiogenic situation (due to blocked working memory capacities), or to deliberate efforts to cognitively regulate anxiety via semantic reinterpretation (reappraisal) of the situation or via the suppression of emotional expressive behavior (Gross, 1998), or that they might also be understood from a predictive coding perspective (Büchel et al., 2014).

Although our data must leave these questions open, we nevertheless believe that the present study makes an important step to understanding the neural bases of a clinically highly important phenomenon, whose further mechanistic dissection might also inspire new forms of anxiety therapy.

\section{References}

Aftanas LI, Golocheikine SA (2001) Human anterior and frontal midline theta and lower alpha reflect emotionally positive state and internalized attention: high-resolution EEG investigation of meditation. Neurosci Lett 310:57-60. CrossRef Medline

Amanzio M, Benedetti F, Porro CA, Palermo S, Cauda F (2013) Activation likelihood estimation meta-analysis of brain correlates of placebo analgesia in human experimental pain. Hum Brain Mapp 34:738-752. CrossRef Medline

Anguera JA, Boccanfuso J, Rintoul JL, Al-Hashimi O, Faraji F, Janowich J,
Kong E, Larraburo Y, Rolle C, Johnston E, Gazzaley A (2013) Video game training enhances cognitive control in older adults. Nature 501:97101. CrossRef Medline

Baas JM, Kenemans JL, Böcker KB, Verbaten MN (2002) Threat-induced cortical processing and startle potentiation. Neuroreport 13:133-137. CrossRef Medline

Benedek M, Kaernbach C (2010) A continuous measure of phasic electrodermal activity. J Neurosci Methods 190:80-91. CrossRef Medline

Benedetti F (2010) No prefrontal control, no placebo response. Pain 148: 357-358. CrossRef Medline

Benedetti F, Maggi G, Lopiano L, Lanotte M, Rainero I, Vighetti S, Pollo A (2003) Open versus hidden medical treatments: the patient's knowledge about a therapy affects the therapy outcome. Prev Treat 6. CrossRef

Benedetti F, Colloca L, Torre E, Lanotte M, Melcarne A, Pesare M, Bergamasco B, Lopiano L (2004) Placebo-responsive Parkinson patients show decreased activity in single neurons of subthalamic nucleus. Nat Neurosci 7:587-588. CrossRef Medline

Benedetti F, Carlino E, Pollo A (2011) How placebos change the patient's brain. Neuropsychopharmacology 36:339-354. CrossRef Medline

Bingel U, Lorenz J, Schoell E, Weiller C, Büchel C (2006) Mechanisms of placebo analgesia: $\mathrm{rACC}$ recruitment of a subcortical antinociceptive network. Pain 120:8-15. CrossRef Medline

Blanchard RJ, Yudko EB, Rodgers RJ, Blanchard DC (1993) Defense system psychopharmacology: an ethological approach to the pharmacology of fear and anxiety. Behav Brain Res 58:155-165. CrossRef Medline

Boucsein W, Fowles DC, Grimnes S, Ben-Shakhar G, Roth WT, Dawson ME, Filion DL, Society for Psychophysiological Research Ad Hoc Committee on Electrodermal Measures (2012) Publication recommendations for electrodermal measurements. Psychophysiology 49:1017-1034. CrossRef Medline

Brookhuis KA, Mulder G, Mulder LJ, Gloerich AB, van Dellen HJ, van der Meere JJ, Ellermann H (1981) Late positive components and stimulus evaluation time. Biol Psychol 13:107-123. CrossRef Medline

Büchel C, Morris J, Dolan RJ, Friston KJ (1998) Brain systems mediating aversive conditioning: an event-related fMRI study. Neuron 20:947-957. CrossRef Medline

Büchel C, Geuter S, Sprenger C, Eippert F (2014) Placebo analgesia: a predictive coding perspective. Neuron 81:1223-1239. CrossRef Medline

Colloca L, Lopiano L, Lanotte M, Benedetti F (2004) Overt versus covert treatment for pain, anxiety, and Parkinson's disease. Lancet Neurol 3:679-684. CrossRef Medline

Cooper NR, Croft RJ, Dominey SJ, Burgess AP, Gruzelier JH (2003) Paradox lost? Exploring the role of alpha oscillations during externally vs. internally directed attention and the implications for idling and inhibition hypotheses. Int J Psychophysiol 47:65-74. CrossRef Medline

Davis M, Walker DL, Miles L, Grillon C (2010) Phasic vs sustained fear in rats and humans: role of the extended amygdala in fear vs anxiety. Neuropsychopharmacology 35:105-135. CrossRef Medline

Di Russo F, Martínez A, Sereno MI, Pitzalis S, Hillyard SA (2002) Cortical sources of the early components of the visual evoked potential. Hum Brain Mapp 15:95-111. CrossRef Medline

Eippert F, Bingel U, Schoell ED, Yacubian J, Klinger R, Lorenz J, Büchel C (2009) Activation of the opioidergic descending pain control system underlies placebo analgesia. Neuron 63:533-543. CrossRef Medline

Ertl M, Hildebrandt M, Ourina K, Leicht G, Mulert C (2013) Emotion regulation by cognitive reappraisal: the role of frontal theta oscillations. Neuroimage 81:412-421. CrossRef Medline

Fanselow MS, Lester LS (1988) A functional behavioristic approach to aversively motivated behavior: predatory imminence as a determinant of the topography of defensive behavior. In: Evolution and learning (Bolles RC, Beecher MD, eds), pp 185-211. Hillsdale, NJ: Erlbaum.

Flaten MA, Aslaksen PM, Lyby PS, Bjørkedal E (2011) The relation of emotions to placebo responses. Philos Trans R Soc Lond B Biol Sci 366:1818 1827. CrossRef Medline

Furmark T, Appel L, Henningsson S, Ahs F, Faria V, Linnman C, Pissiota A, Frans O, Bani M, Bettica P, Pich EM, Jacobsson E, Wahlstedt K, Oreland L, Långström B, Eriksson E, Fredrikson M (2008) A link between serotonin-related gene polymorphisms, amygdala activity, and placeboinduced relief from social anxiety. J Neurosci 28:13066-13074. CrossRef Medline

Gevins A, Smith ME, McEvoy L, Yu D (1997) High-resolution EEG mapping of cortical activation related to working memory: effects of task 
difficulty, type of processing, and practice. Cereb Cortex 7:374-385. CrossRef Medline

Grillon C (2008) Models and mechanisms of anxiety: evidence from startle studies. Psychopharmacology (Berl) 199:421-437. CrossRef Medline

Gross JJ (1998) Antecedent- and response-focused emotion regulation: divergent consequences for experience, expression, and physiology. J Pers Soc Psychol 74:224-237. CrossRef Medline

Hajcak G, MacNamara A, Olvet DM (2010) Event-related potentials, emotion, and emotion regulation: an integrative review. Dev Neuropsychol 35:129-155. CrossRef Medline

Hsieh LT, Ranganath C (2014) Frontal midline theta oscillations during working memory maintenance and episodic encoding and retrieval. Neuroimage 85:721-729. CrossRef Medline

Hsieh LT, Ekstrom AD, Ranganath C (2011) Neural oscillations associated with item and temporal order maintenance in working memory. J Neurosci 31:10803-10810. CrossRef Medline

Huber PJ (1981) Robust statistics. New York: Wiley.

Isreal JB, Wickens CD, Chesney GL, Donchin E (1980) The event-related brain potential as an index of display-monitoring workload. Hum Factors 22:211-224. Medline

Johnson R Jr (1984) P300: a model of the variables controlling its amplitude. Ann N Y Acad Sci 425:223-229. CrossRef Medline

Klimesch W, Sauseng P, Hanslmayr S (2007) EEG alpha oscillations: the inhibition-timing hypothesis. Brain Res Rev 53:63-88. CrossRef Medline

Kok A (2001) On the utility of P3 amplitude as a measure of processing capacity. Psychophysiology 38:557-577. CrossRef Medline

Kolassa IT, Musial F, Mohr A, Trippe RH, Miltner WH (2005) Electrophysiological correlates of threat processing in spider phobics. Psychophysiology 42:520-530. CrossRef Medline

Krummenacher P, Candia V, Folkers G, Schedlowski M, Schönbächler G (2010) Prefrontal cortex modulates placebo analgesia. Pain 148:368374. CrossRef Medline

Lachaux JP, Rodriguez E, Martinerie J, Varela FJ (1999) Measuring phase synchrony in brain signals. Hum Brain Mapp 8:194-208. CrossRef Medline

Leuchter AF, Cook IA, Witte EA, Morgan M, Abrams M (2002) Changes in brain function of depressed subjects during treatment with placebo. Am J Psychiatry 159:122-129. CrossRef Medline

Liu Y, Huang H, McGinnis-Deweese M, Keil A, Ding M (2012) Neural substrate of the late positive potential in emotional processing. J Neurosci 32:14563-14572. CrossRef Medline

Lykken DT, Venables PH (1971) Direct measurement of skin conductance: a proposal for standardization. Psychophysiology 8:656-672. CrossRef Medline

Magliero A, Bashore TR, Coles MG, Donchin E (1984) On the dependence of P300 latency on stimulus evaluation processes. Psychophysiology 21: 171-186. CrossRef Medline

Maris E, Oostenveld R (2007) Nonparametric statistical testing of EEG- and MEG-data. J Neurosci Methods 164:177-190. CrossRef Medline

Mobbs D, Petrovic P, Marchant JL, Hassabis D, Weiskopf N, Seymour B, Dolan RJ, Frith CD (2007) When fear is near: threat imminence elicits prefrontal-periaqueductal gray shifts in humans. Science 317:1079-1083. CrossRef Medline

Mulert C, Jäger L, Schmitt R, Bussfeld P, Pogarell O, Möller HJ, Juckel G, Hegerl U (2004) Integration of fMRI and simultaneous EEG: towards a comprehensive understanding of localization and time-course of brain activity in target detection. Neuroimage 22:83-94. CrossRef Medline

Nitzan U, Lichtenberg P (2004) Questionnaire survey on use of placebo. BMJ 329:944-946. CrossRef Medline

Nunez PL, Srinivasan R, Westdorp AF, Wijesinghe RS, Tucker DM, Silberstein RB, Cadusch PJ (1997) EEG coherency. I: Statistics, reference electrode, volume conduction, Laplacians, cortical imaging, and interpretation at multiple scales. Electroencephalogr Clin Neurophysiol 103:499-515. CrossRef Medline

Ochsner KN, Gross JJ (2005) The cognitive control of emotion. Trends Cogn Sci 9:242-249. CrossRef Medline
Oostenveld R, Fries P, Maris E, Schoffelen JM (2011) FieldTrip: open source software for advanced analysis of MEG, EEG, and invasive electrophysiological data. Comput Intell Neurosci 2011:156869. CrossRef Medline

Petrovic P, Dietrich T, Fransson P, Andersson J, Carlsson K, Ingvar M (2005) Placebo in emotional processing: induced expectations of anxiety relief activate a generalized modulatory network. Neuron 46:957-969. CrossRef Medline

Pfurtscheller G, Stancák A Jr, Neuper C (1996) Event-related synchronization (ERS) in the alpha band- an electrophysiological correlate of cortical idling: a review. Int J Psychophysiol 24:39-46. CrossRef Medline

Polich J (2007) Updating P300: an integrative theory of P3a and P3b. Clin Neurophysiol 118:2128-2148. CrossRef Medline

Polich J, Kok A (1995) Cognitive and biological determinants of P300: an integrative review. Biol Psychol 41:103-146. CrossRef Medline

Price DD, Finniss DG, Benedetti F (2008) A comprehensive review of the placebo effect: recent advances and current thought. Annu Rev Psychol 59:565-590. CrossRef Medline

Rodgers RJ (1997) Animal models of "anxiety": where next? Behav Pharmacol 8:477-496; discussion 497-504. CrossRef Medline

Sauseng P, Hoppe J, Klimesch W, Gerloff C, Hummel FC (2007) Dissociation of sustained attention from central executive functions: local activity and interregional connectivity in the theta range. Eur J Neurosci 25:587593. CrossRef Medline

Scharmüller W, Leutgeb V, Schäfer A, Köchel A, Schienle A (2011) Source localization of late electrocortical positivity during symptom provocation in spider phobia: an sLORETA study. Brain Res 1397:10-18. CrossRef Medline

Scharmüller W, Leutgeb V, Schäfer A, Schienle A (2012) Investigating phobic specificity with standardized low resolution brain electromagnetic tomography (sLORETA). Brain Res 1477:74-82. CrossRef Medline

Schienle A, Übel S, Scharmüller W (2014) Placebo treatment can alter primary visual cortex activity and connectivity. Neuroscience 263:125-129. CrossRef Medline

Schmidt L, Braun EK, Wager TD, Shohamy D (2014) Mind matters: placebo enhances reward learning in Parkinson's disease. Nat Neurosci 17:17931797. CrossRef Medline

Sherman R, Hickner J (2008) Academic physicians use placebos in clinical practice and believe in the mind-body connection. J Gen Intern Med 23:7-10. CrossRef Medline

Spielberger C (1985) Assessment of state and trait anxiety: conceptual and methodological issues. Southern Psychol 2:6-16.

Stein DJ, Baldwin DS, Dolberg OT, Despiegel N, Bandelow B (2006) Which factors predict placebo response in anxiety disorders and major depression? An analysis of placebo-controlled studies of escitalopram. J Clin Psychiatry 67:1741-1746. CrossRef Medline

Sugarman MA, Loree AM, Baltes BB, Grekin ER, Kirsch I (2014) The efficacy of paroxetine and placebo in treating anxiety and depression: a metaanalysis of change on the Hamilton Rating Scales. PLoS One 9:e106337. CrossRef Medline

Wager TD, Rilling JK, Smith EE, Sokolik A, Casey KL, Davidson RJ, Kosslyn SM, Rose RM, Cohen JD (2004) Placebo-induced changes in FMRI in the anticipation and experience of pain. Science 303:1162-1167. CrossRef Medline

Walker DL, Toufexis DJ, Davis M (2003) Role of the bed nucleus of the stria terminalis versus the amygdala in fear, stress, and anxiety. Eur J Pharmacol 463:199-216. CrossRef Medline

Weymar M, Bradley MM, Hamm AO, Lang PJ (2013) When fear forms memories: threat of shock and brain potentials during encoding and recognition. Cortex 49:819-826. CrossRef Medline

Zahn TP, Rapoport JL, Thompson CL (1981) Autonomic effects of dextroamphetamine in normal men: implications for hyperactivity and schizophrenia. Psychiatry Res 4:39-47. CrossRef Medline

Zhang W, Qin S, Guo J, Luo J (2011) A follow-up fMRI study of a transferable placebo anxiolytic effect. Psychophysiology 48:1119-1128. CrossRef Medline 